\title{
Linfocitos $\mathbf{T}$ reguladores $\mathbf{y}$ respuesta inmune
}

\author{
ULISES VERGARA C. ${ }^{1,2}$
}

1 Departamento de Medicina Preventiva y Escuela de Postgrado y Postítulo, Facultad de Ciencias Veterinarias, y Pecuarias, Universidad de Chile.

2 Escuela de Postgrado, Facultad de Medicina, Universidad de Chile.

\begin{abstract}
REGULATORY T LYMPHOCYTES AND IMMUNE RESPONSE

Immune regulation or immune suppression has been proposed to play a key role to maintain tolerance to self antigens, avoid development of autoimmune diseases, prevent runaway responses to pathogens or allergens, function to temper the massive proinflammatory stimulus created by bacteria within the gut, help maintain a balance with commensal microflora and facilitate tumors' escape from immune monitoring. Although several distinct cell lineages may participate in these control of the immune response, an important population of CD4+ T cells, known as regulatory T cells, play key roles in maintaining tolerance to self antigens. These regulatory $\mathrm{T}$ cells can suppress the proliferation and/or functions of various immune cells including CD4+ T cells, CD8+ T cells, NKT cells, dendritic cells (DCs), monocytes/macrophages, B cells, and NK cells. Naturally occurring CD4+ CD25+ Foxp3+ regulatory $\mathrm{T}$ cells (nTregs) represent $5-10 \%$ of peripheral CD4 $\mathrm{T}$ cells, and recent studies in the mouse have shown that these cells are critical regulators of immune tolerance. In recent years progress in characterizing many of these cell types has been accelerate, most notably by discovery of the relevance of the transcription factor Foxp3. It is established that under specific conditions naïve CD4+CD25-Foxp3- $\mathrm{T}$ cells can be converted into Foxp3+ inducible regulatory $\mathrm{T}$ cells (iTregs) and several conversion/expansion protocols have been described. Such protocols usually involve T cell stimulation under conditions of cytokine modification where transforming growth factor-beta (TGF-b) has been shown to play a critical role. These inducible populations of Tregs are characterized by expression of Foxp 3 and the ability to inhibit the proliferation of effector T cells in vitro. Moreover, several studies have shown that these ex vivo generated Foxp3+ cells can regulate $\mathrm{T}$ cell responses in vivo following adoptive transfer into immunodeficient recipients.
\end{abstract}

Key words: CD25+CD4+ regulatory T cells, Foxp,3, TGF- $\beta$, CTLA-4, tolerance, autoimmunity.

\section{RESUMEN}

La regulación inmune o inmunosupresión desempeña un rol trascendental en la mantención de la tolerancia a antígenos propios, evita la aparición de enfermedades autoinmunes, controla el desarrollo

Av. Santa Rosa 11735, La Pintana, Santiago, Chile. Correo 2, Casilla 15, La Granja.

Av. Independencia 1027, Santiago, Chile.

E:mail: uvergara@uchile.cl 
de una respuesta inmune exagerada frente a agentes patógenos o frente a distintos alergenos, ayuda a disminuir el masivo estímulo proinflamatorio de la microflora comensal del tracto digestivo y favorece el escape de las células tumorales al control inmunológico. Aunque distintas poblaciones celulares pueden participar en este importante control de la respuesta inmune, un grupo particular de linfocitos TCD4+, conocidos como linfocitos T reguladores, resulta fundamental en la mantención de la tolerancia a antígenos propios. Estos linfocitos T reguladores pueden suprimir la proliferación y/o función de diversas células del sistema inmune, incluyendo linfocitos TCD4+, linfocitos TCD8+, células NKT, células dendríticas, monocitos/macrófagos, linfocitos B y células NK. Los linfocitos T reguladores naturales CD4+ CD25+ Foxp3+ (nTregs) representan el 5-10\% de los linfocitos T CD4 periféricos, y estudios en ratón han demostrado que estas células son reguladores esenciales en la mantención de la tolerancia inmunológica. En los últimos años los avances en la caracterización de Tregs han sido vertiginosos, sobre todo por el descubrimiento del relevante rol desempeñado por el factor de transcripción Foxp3. Se ha observado que en determinadas condiciones in vitro, linfocitos $\mathrm{T}$ vírgenes CD4+ CD25- Foxp3- se pueden convertir en linfocitos T reguladores inducibles Foxp3+ (iTregs), mediante diversos protocolos de conversión y/o expansión. Estos protocolos generalmente implican la activación de linfocitos TCD4+ bajo distintas condiciones experimentales, incluyendo el agregado exógeno de distintas citoquinas, como el factor de.crecimiento transformante-beta (TGF- $\beta$ ), que parece cumplir una función crítica en los procesos de activación y diferenciación. Estas poblaciones inducibles de Tregs se caracterizan por la expresión de Foxp3 y por la capacidad de inhibir la proliferación de de linfocitos $\mathrm{T}$ efectores in vitro. Diversos estudios han demostrado además, que estos linfocito Foxp3+, generados ex vivo, pueden regular la respuesta celular T in vivo, luego de su transferencia adoptiva en receptores inmunodeficientes.

Palabras clave: Linfocitos T reguladores CD25+CD4+, Foxp,3, TGF- $\beta$, CTLA-4, tolerancia, atutoinmunidad.

\section{INTRODUCCIÓN}

El sistema inmune de los vertebrados superiores proporciona una defensa inmunológica específica y muy eficiente contra los agentes infecciosos, previene el desarrollo de autoinmunidad y controla el desarrollo de tumores. Ello obedece a que el desarrollo de una respuesta inmune está sujeta al control de mecanismos reguladores que pueden ser intrínsecos como la eliminación o delección de linfocitos o su inactivación funcional o anergia clonal que se produce en los órganos linfoides primarios (timo para linfocitos $\mathrm{T}$ y médula ósea para linfocitos B) o bien extrínsecos como la supresión producida por distintos linfocitos $\mathrm{T}$ reguladores (Tregs), que mantienen la tolerancia a antígenos propios en la periferia (Asano y col., 1996, Suri-Payer y col., 1998, Walker y Abbas, 2002).

La característica más sobresaliente del sistema inmune es su capacidad para desarrollar distintos tipos de respuesta frente a diferentes antígenos o patógenos. Así, los linfocitos TCD4+ desempeñan un rol fundamental en la función del sistema inmune, puesto que colaboran con linfocitos B en el desarrollo de una respuesta humoral mediada por anticuerpos, estimulan y mantienen una respuesta celular $\mathrm{T}$ citotóxica mediada por linfocitos $\mathrm{TCD} 8+$, modulan la función de macrófagos, regulan la respuesta inmune contra una gran variedad de agentes patógenos y controlan la respuesta a antígenos propios, previniendo el desarrollo de autoinmunidad.

En 1986 se observó que los linfocitos TCD4+, pueden separarse en dos subpoblaciones de linfocitos de colaboración o ayuda, (T helper o Th), llamadas Th1 y Th2, caracterizadas por la secreción de un particular patrón de citoquinas. (Mossmann y col., 1986).

Los linfocitos Th1 se caracterizan por la secreción de Interferon gama (IFN- $\gamma$ ) y son muy efectivos contra virus y bacterias intracelulares a través de la activación de células natural killer (células NK), y la activación y expansión de linfocitos $\mathrm{T}$ citotóxicos.

Los linfocitos Th2 en cambio, secretan Interleuquina-4 (IL-4), Interleuquina-5 (IL-5) e Interleuquina-13 (IL-13), que activan la destrucción 
de patógenos a través de anticuerpos $\operatorname{IgE}$ y de eosinófilos.

Más tarde, en el año 2003, se describió una tercera subpoblación de linfocitos de colaboración TCD4+, llamados Th17 o proinflamatorios, caracterizados por la secreción de las citoquinas IL-17 e IL-22 y por su importante participación en la defensa contra bacterias extracelulares y hongos (Aggarwal y col., 2003, Murphy y col., 2003). De manera casi simultánea, pudo demostrarse que linfocitos TCD4+ vírgenes pueden ser inducidos a diferenciarse in vitro, en linfocitos $T$ reguladores que expresan el factor de transcripción Forkhead box P3 (Foxp3), como consecuencia de la activación a través de su TcR específico ( $\mathrm{T}$ cell receptor), en presencia de las citoquinas TGF- $\beta$ ( Transforming Growth Factor beta) e IL-2 (Chen y col., 2003).

La diferenciación de estas cuatro subpoblaciones de linfocitos TCD4+, a partir de linfocitos $\mathrm{T}$ vírgenes, depende de las citoquinas presentes durante la activación celular y hoy sabemos que está además regulada por la expresión de distintos factores de transcripción como T-bet y Signal Transducer and Activator of Transcription-4 (STAT-4) para los linfocitos Th1, GATA3 y STAT6 para los linfocitos Th2, ROR $\gamma$ t y STAT3 para los Th17 y Foxp3 y STAT5 para los linfocitos Tregs (Tabla 1).

Así, los linfocitos Th1 pueden generarse durante la exposición a citoquinas como IL-12 e Interferón gama (IFN- $\gamma$ ), para conferir protección contra virus y bacterias intracelulares, mientras las interleuquinas IL-4, IL-5 e IL-13 inducen la diferenciación Th2 que contribuyen a la activación de linfocitos $\mathrm{B}$ y promueven la inmunidad mediada por anticuerpos y protegen contra las infecciones parasitarias. Pequeñas concentraciones de IL- 6 y TGF- $\beta$ promueven, en cambio, la diferenciación de linfocitos Th17, que secretan
IL-17 y proporcionan protección contra bacterias extracelulares y controlan el desarrollo de autoinmunidad. Finalmente, la presencia de TFG- $\beta$, IL-2 y de ácido retinoico induce la diferenciación de linfocitos Tregs, que resultan fundamentales en la mantención de la tolerancia periférica (Glimher y Murphy, 2000, Kang y col., 2007, Zhu y Paul, 2008, Locksley, 2009) (Figura $1)$.

Los linfocitos $\mathrm{T}$ reguladores constituyen un grupo particular de linfocitos TCD4+, que desempeñan un rol fundamental en la mantención de la tolerancia a antígenos propios, evitan la aparición de enfermedades autoinmunes, controlan el desarrollo de una respuesta inmune exagerada $o$ aberrante frente a agentes patógenos o frente a distintos alergenos, ayudan a disminuir el masivo estímulo proinflamatorio de la microflora comensal del tracto digestivo y favorecen el escape de las células tumorales al control inmunológico (Sakaguchi y col., 2006, Yamaguchi y col., 2006, Sakaguchi y col., 2008, Belkaid y Tarbell 2009). Las poblaciones celulares que son suprimidas por estos linfocitos $\mathrm{T}$ regs, incluyen linfocitos TCD4+, linfocitos TCD8+, linfocitos NKT, células dendríticas (CDs), monocitos/macrófagos, linfocitos B y células natural killer (células NK) (Kim 2006, Ziegler 2006).

\section{Subpoblaciones de linfocitos $\mathrm{T}$ reguladores}

Los linfocitos $\mathrm{T}$ reguladores pueden desarrollarse tanto en el timo como en la periferia y distintas subpoblaciones actúan de manera diferente, puesto que mientras algunas producen distintas citoquinas inmunosupresoras, otras requieren de contacto directo célula-célula para inhibir el desarrollo de la respuesta inmune.

Desde que en 1995 se demostró en ratones

Tabla 1. Factores de transcripción expresados y citoquinas secretadas por distintas subpoblaciones de linfocitos TCD4+

\begin{tabular}{lll}
\hline Subpoblación TCD4+ & Factores de transcripción & Citoquinas secretadas \\
\hline Th1 & T-bet, STAT1, STAT4 & IFN $\gamma$, IL-2, TNF, Linfotoxina \\
Th2 & GATA3, STAT6 & IL-4, IL-5, IL-6, IL-10, IL-13 \\
Th17 & ROR $\gamma$ t, ROR $\alpha$, STAT3 & IL-17, IL-21, IL-22, TNF \\
Treg & Foxp3, STAT5 & IL-10, TGF $\beta$ \\
\hline
\end{tabular}

ROR: retinoic-acid-receptor related orphan receptor. 


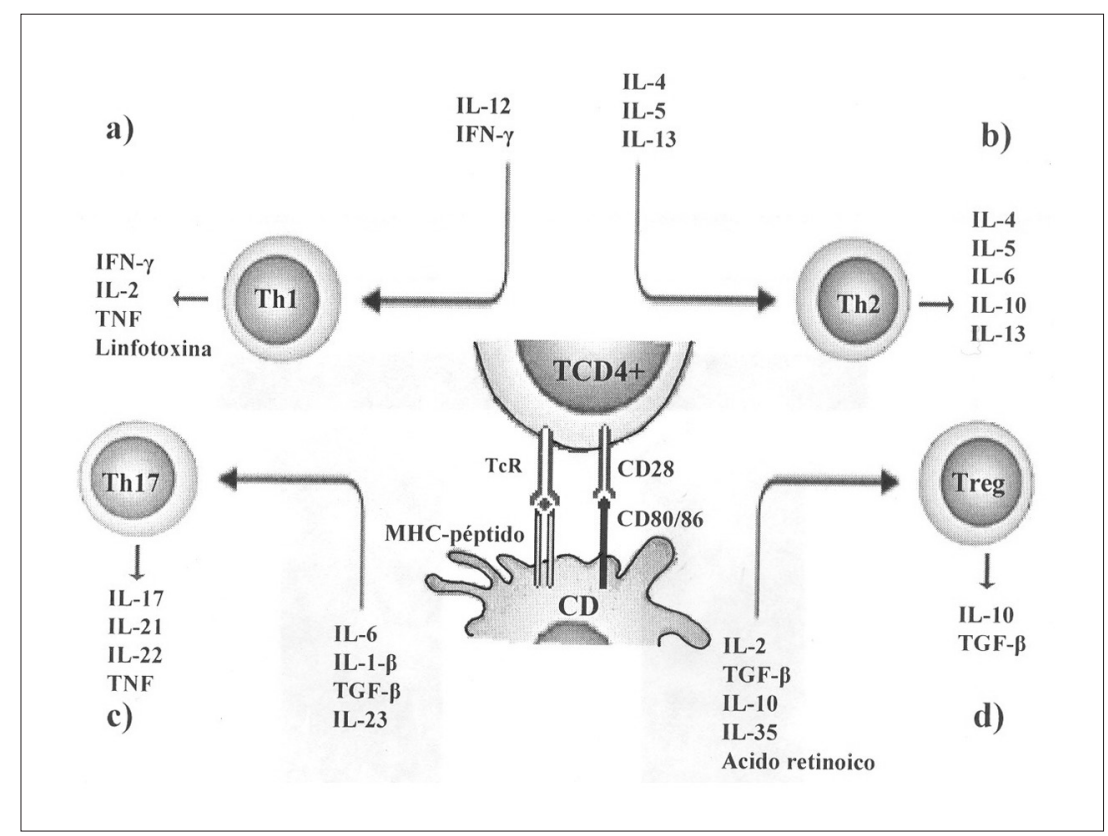

Figura 1. Activación y diferenciación de linfocitos TCD4+. La activación y diferenciación de linfocitos TCD4+ requiere el reconocimiento por el TcR, del complejo MHC/péptido presentado por la célula dendrítica (CD), señales accesorias de coestimulación (como la interacción CD28-CD80/86) y la presencia de citoquinas que inducen la expansión clonal y diferenciación de los linfocitos. a) En presencia de IL-12 e IFN- $\gamma$, se generan linfocitos Th1 que secretan IL-2, IFN- $\gamma$, TNF y Linfotoxina. b) Las citoquinas IL-4, IL-6, e IL-13 inducen la diferenciación de la subpoblación Th2, que secreta IL-4, Il-5, IL-6, IL-10 e IL-13. c) La presencia de IL-1, $\beta$, IL-6, IL-23 y de TGF- $\beta$, activa la diferenciación de linfocitos Th17, que secretan IL-17, IL-21 e IL-22. d) Finalmente, en presencia de TFG- $\beta$, Il-2, IL-10, IL-356 y ácido retinoico, se induce la diferenciación de linfocitos T reguladores, que secretan IL-10 y TGF- $\beta$.

que linfocitos TCD4+ CD25+ tienen actividad inmunosupresora (Sakaguchi y col., 1995), se han descrito distintas subpoblaciones de linfocitos T reguladores (Assemann y Powrie, 1998), que contribuyen al mantenimiento de la tolerancia a antígenos propios y a controlar el desarrollo de la respuesta inmune a antígenos extraños (Chen $y$ col., 2003, Fischer y col., 2005; Jiang y Chess, 2006; Chen, y col., 2008; Ito y col., 2008, Corthay 2009).

Luego de su activación, los linfocitos TCD4+ expresan CD25, que corresponde a la cadena alfa del receptor para la citoquina IL-2, la cual actúa como un factor fundamental para la expansión clonal de los linfocitos T (Robb y col., 1981, Yamazaki y col., 2003, Allan y col., 2007).

Los linfocitos Tregs pueden separarse en dos subpoblaciones distintas: linfocitos Tregs naturales CD4+ CD25+ (nTregs), que se generan en el timo y se incorporan al repertorio linfocitario periférico como linfocitos Tregs funcionales o maduros (Hori y col., 2003, Cupedo y col., 2005) $\mathrm{y}$ linfocitos $\mathrm{T}$ reguladores inducibles (iTregs), que se generan en la periferia a partir de linfocitos vírgenes TCD4+ CD25- o que se expanden a partir de linfocitos T CD4+ CD25+ (Karim y col., 2004, Vukmanovic-Stejic y col., 2006). De esta manera, diferentes subpoblaciones de linfocitos Tregs con distinto origen, distinto fenotipo $\mathrm{y}$ distintos mecanismos de supresión, pueden mantener la tolerancia a antígenos propios y controlar el desarrollo de la respuesta inmune frente a antígenos extraños.

Como ocurre con todos los linfocitos $\mathrm{T}$, el desarrollo intratímico de los linfocitos Tregs depende no sólo de señales de activación transducidas a través del TcR, que reconoce y une con alta afinidad antígenos propios, sino también de IL-2 y de señales de activación transducidas a través de la molécula de membrana y coestimulación CD28, que debe interactuar con CD80 y/o CD86, expresados en la superficie de células presentadoras de antígeno activadas o maduras (Figura 1). Además, la expresión del factor de 
transcripción Foxp3 resulta fundamental, tanto para la diferenciación nTregs en el timo, como para el desarrollo de su función inmunosupresora (Fontenot $y$ col., 2003; Hori y col., 2003; Khattri y col., 2003).

\section{Fenotipo y mecanismo de supresión de los linfocitos $T$ reguladores}

En la actualidad, el marcador más confiable para definir y aislar linfocitos Tregs es el factor de transcripción Foxp3 (Fontenot y col., 2003, Hori y col., 2003, Khattri y col., 2003). La expresión de Foxp3 se encuentra altamente restringida a linfocitos $\mathrm{T} \alpha \beta$, siendo casi indetectable en linfocitos $\mathrm{T} \gamma \delta$, linfocitos $\mathrm{B}$, células $\mathrm{NK}$, macrófagos y células dendríticas. Aún cuando la expresión de Foxp3 parece restringida a linfocitos T CD4+, existen linfocitos T CD8+ que también pueden expresar este factor de transcripción.

Ahora bien, aún cuando Foxp3 es el marcador más confiable de los Tregs, existen otras moléculas de membrana, como CD25, CTLA4 (Cytotoxic T lymphocyte-associated antigen 4), GITR (Glucocorticoid-Inducible Tumor necrosis factor Receptor), CD127 y Lag-3, que se han asociado a la funcionalidad de estos linfocitos. En términos generales, la caracterización fenotípica de los linfocitos $\mathrm{T}$ reguladores incluye moléculas como CD62L, CD103, CD49d, CCR4, CCR5, CCR8 que se asocian a la recirculación y homing linfocitario y, además, moléculas como CD101, CTLA-4, Lag-3, CD103 Galectin-1 y CD39, que se han asociado a la función supresora (Mottet y Golshayan 2007).

Los mecanismos mediante los cuales los linfocitos $\mathrm{T}$ reguladores ejercen su función supresora de la respuesta inmune, incluyen, tanto mecanismos dependientes de la secreción de citoquinas inhibitorias, como de mecanismos independientes de citoquinas y que incluyen citotoxicidad o citolisis, disrupción metabólica y la modulación y maduración de células presentadoras de antígeno, en particular de las células dendríticas.

Entre las citoquinas inhibitorias se encuentran IL-10 y TGF- $\beta$ e IL-35, que tienen además la capacidad de inducir la diferenciación de linfocitos $\mathrm{T}$ reguladores, tanto in vivo como in vitro. Entre estas citoquinas, la más importante parece ser TGF- $\beta$. En intestino, por ejemplo, la expresión de Foxp3 en linfocitos $\mathrm{T}$ vírgenes depende de la expresión local de TGF- $\beta$ y de ácido retinoico (un metabolito de la vitamina A), que junto a TGF- $\beta$ activa la expresión de este factor de transcripción propio de linfocitos Tregs (Chen $y$ col., 2003, Sun y col., 2007, Coombes $y$ col., 2007). Además de su rol en la generación y homeostasis periférica de los Tregs, TGF- $\beta$ es una molécula efectora de la inmunosupresión producida por estos linfocitos.

El mecanismo de supresión mediado por citoxicidad (citolisis), se ha asociado a la secreción de perforina y de granzimas, de manera similar a lo que ocurre con células NK y Linfocitos T citotóxicos TCD8+. En particular, granzima B tiene la capacidad de inducir apoptosis de linfocitos $\mathrm{T}$ efectores, mediante un mecanismo independiente de perforina (Gondek $y$ col., 2005). Además, en los últimos años se ha observado que linfocitos $\mathrm{T}$ reguladores producen galectina-1 que induce la apoptosis de linfocitos T (Garin y col., 2007). Por otra parte, la fagocitosis de linfocitos apoptóticos puede activar la producción de TGF- $\beta$ en células dendríticas y macrófagos, lo que conduce a la supresión de la respuesta inmune (Perruche $y$ col., 2008).

El antígeno-4 asociado a linfocitos T citotóxicos (CTLA-4) es un receptor de inhibición, cuya expresión se induce como consecuencia de la activación de linfocitos $\mathrm{T}$ vírgenes, pero que se expresa en niveles particularmente altos en linfocitos T reguladores (Read y col., 2000, Takahashi y col., 2000).

Además de su efecto sobre los linfocito $\mathrm{T}$ efectores de la respuesta inmune, los linfocitos $\mathrm{T}$ reguladores pueden modular la maduración y funcionamiento de las células dendríticas, las cuales son fundamentales para la activación de los linfocitos efectores a los que, no sólo presentan fragmentos antigénicos unidos a moléculas de presentación codificadas por el complejo mayor de histocompatibilidad (MHC: Major Histocompatibilkity Complex), sino que también proporcionan las necesarias señales accesorias de coestimulación (Figura 1). Experimentos in vivo han revelado que la interacción directa entre CD80 y CD86, expresado en la membrana de células dendríticas maduras, con CTLA-4 expresado en la superficie de linfocitos Tregs, disminuye el efecto activador de las células dendríticas, sobre los linfocitos $\mathrm{T}$ efectores (Takahashi y col., 
1998; Read y col., 2000).

Antecedentes adicionales sugieren que no sólo las interacciones entre CTLA-4 de Tregs y CD80/86 de las células dendríticas, pueden modificar la capacidad de estas últimas para activar linfocitos $\mathrm{T}$ efectores, sino que citoquinas como IL-10 y TGF- $\beta$ desempeñan también un rol importante (Misra y col., 2004; Workman y Vignali 2005; Kryczek y col., 2006; Liang y col., 2008).

Recientemente se ha sugerido además, que los Tregs pueden inhibir la maduración de las DCs a través de Lag-3 (también conocida como CD223), molécula homóloga a CD4 y que, como ésta, se une con alta afinidad a moléculas de MHCde clase II, expresadas en DC inmaduras, transduciendo señales de inhibición que suprimen su maduración y por lo tanto, su capacidad inmunoestimuladora (Liang y col., 2008).

Se han postulado diversos mecanismos adicionales de inmunosupresión en los Tregs, entre lo que se encuentran la modulación de los niveles de indoleamina 2, 3-dioxigenasa (IDO) y de adenosina.

IDO es una potente molécula reguladora que induce la producción de metabolitos pro-apoptóticos a partir del catabolismo de triptófano, lo que conduce a la supresión de linfocitos T efectores, a través de un mecanismo dependiente de las interacción CTLA-4 y CD80/CD86 entre Tregs y células dendríticas. (Fallarino y col., 2003; Gurtner $y$ col., 2003, Mellor and Munn 2004). Se ha sugerido que el mecanismo de acción de IDO estaría mediado por la depleción de triptofano y la producción del catabolito tóxico quinurenina (Mellor y Munn, 2004).

Adenosina, en cambio, puede actuar como señal de estrés tisular e inducir tolerancia inmunológica a través de un mecanismos que no ha sido claramente dilucidado (Naganuma y col., 2006, Deaglio $y$ col., 2007).

Finalmente, los linfocitos T reguladores pueden ejercer su función inmunosupresora supresora a través de la disrupción metabólica de células efectoras, mediante mecanismos dependientes de la expresión de las enzimas CD39 y CD73 que generan adenosina extracelular que suprime la función de los linfocitos $\mathrm{T}$ efectores, a través de la activación del receptor de adenosina $2 \mathrm{~A}\left(\mathrm{~A}_{2 \mathrm{~A}} \mathrm{R}\right)$ (Kobie y col., 2006; Borsellino y col., 2007, Deaglio y col., 2007). La unión de adenosina a este receptor no sólo inhibe la función efectora de los linfocitos $\mathrm{T}$, sino que también promueve la generación de iTregs, al inhibir la producción de IL-6 y aumentar la secreción de TGF- $\beta$.

\section{REFERENCIAS}

1.- ALLAN SE, CROME SQ, CRELLIN NK, PASSERINI L, STEINER TS, BACCHETTA R, RONCAROLO MG, LEVINGS MK. 2007. Activation-induced FOXP3 in human $\mathrm{T}$ effector cells does not suppress proliferation or cytokine production. Int Immunol 19: 345-354.

2.- AGGARWAL S, GHILARDI N, XIE MH, DE SAUVAGE FJ, GURNEY AL. 2003. Interleukin-23 promotes a distinct CD4Tcell activation state characterized by the production of interleukin-17. J Biol Chem 278: 1910-1914.

3.- ASANOM, TODAM, SAKAGUCHIN, SAKAGUCHI S. 1996. Autoimmune disease as a consequence of developmental abnormality of a $\mathrm{T}$ cell subpopulation. J Exp Med 184: 387-396.

4.- ASSEMAN C, POWRIE F. 1998. Interleukin-10 is a growth factor for a population of regulatory $\mathrm{T}$ cells. Gut 42: 157-158.

5.- BELKAID Y, TARBELL K. 2009. Regulatory T cells in the control of host-microorganism interactions. Annu. Rev Immunol 27: 551-589.

6.- BORSELLINO G, KLEINEWIETFELD M, DI MITRI D, STERNJAK A, DIAMANTINI A, GIOMETTO, R, HOPNER S, CENTONZE D, BERNARDI G, DELL'ACQUA ML, ROSSINI PM, BATTISTINI L, RÖTZSCHKE O, FALK K. 2007. Expression of ectonucleotidase CD39 by Foxp3+ Treg cells: hydrolysis of extracellular ATP and immune suppression. Blood 110: 1225-1232.

7.- CHEN W, JIN W, HARDEGEN N, LEI KJ, LI L, MARINOS N, MCGRADY G, WAHL SM. 2003. Conversion of peripheral CD4+CD25- naiveT cells to $\mathrm{CD} 4+\mathrm{CD} 25+$ regulatory $\mathrm{T}$ cells by TGF- $\beta$ induction of transcription factor Foxp3. J Exp Med 198: 1875-1886.

8.- CHEN ML, YAN BS, BANDO Y, KUCHROO VK, WEINER HL. 2008. Latency-associated peptide identifies a novel $\mathrm{CD} 4+\mathrm{CD} 25+$ regulatory $\mathrm{T}$ cell subset with TGFbeta-mediated function and enhanced suppression of experimental autoimmune encephalomyelitis. J Immunol 180: 7327-7337.

9.- COOMBES JL, SIDDIQUI KR, ARANCIBIA-CARCAMO CV, HALL J, SUN CM, BELKAID, Y, POWRIE F. 2007. A functionally specialized population of mucosal CD103+ DCs induces Foxp3+ regulatory $\mathrm{T}$ cells via a TGF-beta and retinoic acid-dependent mechanism. J Exp Med 204: 1757-1764.

10.- CORTHAY A. 2009. How do regulatory T cells work?. Scand J Immunol 70: 326-336.

11.- CUPEDO T, NAGASAWA M, WEIJER K, BLOM B, SPITS H. 2005. Development and activation of regulatory $\mathrm{T}$ cells in the human fetus. Eur J Immunol 35: 383-390.

12.- DEAGLIO S, DWYER KM, GAO W, FRIEDMAN D, USHEVA A, ERAT A. CHEN JF. ENJYOJI K, LINDEN J, OUKKA M, KUCHROO VK, STROM 
TB, ROBSON SC. 2007. Adenosine generation catalyzed by CD39 and CD73 expressed on regulatory $\mathrm{T}$ cells mediates immune suppression. J Exp Med 204: 1257-1265.

13.- FALLARINO F, GROHMANN U, HWANG KW, ORABONA C, VACCA C, BIANCHI R, BELLADONNA ML, FIORETTI MC, ALEGRE ML, PUCECETTI P. 2003. Modulation of tryptophan catabolism by regulatory T cells. Nat Immunol 4: 1206-1212.

14.- FISCHER K, VOELKL S, HEYMANN J, PRZYBYLSKI GK, MONDAL K, LAUMER M, KUNZSCHIGHART L, SCHMIDT CA, ANDREESEN R, MACKENSEN A. 2005. Isolation and characterization of human antigen-specific TCR alpha beta+ CD4(-) CD8- double-negative regulatory $\mathrm{T}$ cells. Blood 105: 2828-2835.

15.- FONTENOT JD, GAVIN MA, RUDENSKY AY. 2003. Foxp3 programs the development and function of CD4+CD25+ regulatory T cells. Nat Immunol 4: 330336.

16.- GARIN MI, CHU CC, GOLSHAYAN D, CERNUDAMOROLLON E, WAIT R, LECHLER RI. 2007. Galectin-1: a key effector of regulation mediated by CD4+CD25+ T cells. Blood 109: 2058-2065.

17.- GLIMCHER LH, MURPHY KM. 2000. Lineage commitment in the immune system: The $\mathrm{T}$ helper lymphocyte grows up. Genes Dev 14: 1693-1711.

18.- GONDEK DC, LU LF, QUEZADA SA, SAKAGUCHI S, NOELLE RJ. 2005. Cutting edge: contact-mediated suppression by CD4+CD25+ regulatory cells involves a granzyme B-dependent, perforin-independent mechanism. J Immunol 174: 1783-6.

19.- GURTNER GJ, NEWBERRY RD, SCHLOEMANN SR, MCDONALD KG, STENSON WF. 2003. Inhibition of indoleamine 2,3-dioxygenase augments trinitrobenzene sulfonic acid colitis in mice. Gastroenterology 125: $1762-1773$.

20.- HORI S, NOMURA T, SAKAGUCHI S. 2003. Control of regulatory $\mathrm{T}$ cell development by the transcription factor Foxp3. Science 299: 1057-1061.

21.- ITO T, HANABUCHI S, WANG YH, PARK WR, ARIMA K, BOVER L, QIN FX, GILLET M, LIU YJ. 2008. Two functional subsets of FOXP3+ regulatory $\mathrm{T}$ cells in human thymus and periphery. Immunity 28 : 870-880.

22.- JIANG H, CHESS L. Regulation of immune responses by T cells. 2006. N Engl J Med 354: 1166-1176.

23.- KANG SG, LIM HW, ANDRISANI OM, BROXMEYER HE, KIM CH. 2007. Vitamin A Metabolites Induce Gut-Homing FoxP3 Regulatory T Cells. J Immunol 179: 3724-3733.

24.- KARIM M, KINGSLEY CI, BUSHELL AR, SAWITZKI BS, WOOD KJ. 2004. Alloantigen-induced $\mathrm{CD} 25+\mathrm{CD} 4+$ regulatory $\mathrm{T}$ cells can develop in vivo from CD25-CD4+ precursors in a thymus-independent process. J Immunol 172: 923-928.

25.- KHATTRI R, COX T, YASAYKO SA, RAMSDELL F. 2003. An essential role for Scurfin in CD4+CD25+ T regulatory cells. Nat Immunol 4: 337-342.

26.- KIM CH. 2006. Migration and function of FoxP3 ${ }^{+}$ regulatory $\mathrm{T}$ cells in the hematolymphoid system. Exp Hematol 34: 1033-1040.

27.- KOBIE JJ, SHAH PR, YANG L, REBHAHN JA,
FOWELL DJ, MOSMANN TR. 2006. T regulatory and primed uncommitted CD4 T cells express CD73, which suppresses effector CD4 T cells by converting 5 '-adenosine monophosphate to adenosine. J Immunol 177: 6780-6786.

28.- KRYCZEK I, WEI S, ZOU L, ZHU G, MOTTRAM P, XU H, CHEN L, ZOU W. 2006. Cutting edge: induction of B7-H4 on APCs through IL-10: novel suppressive mode for regulatory T cells. J Immunol 177: 40-44.

29.- LIANGB, WORKMANC,LEEJ, CHEWC, DALEBM, COLONNA L, FLORES M, LI N, SCHWEIGHOFFER E, GREENBERG S, TYBULEWICZ V, VIGNALI D, CLYNES R. 2008. Regulatory T cells inhibit dendritic cells by lymphocyte activation gene-3 engagement of MHC class II. J Immunol 180: 5916-5926.

30.- LOCKSLEY RM. 2009. Nine lives: Plasticity among T helper cell subsets. J Exp Med 206: 1643-1646.

31.- MISRA N, BAYRY J, LACROIX-DESMAZES S, KAZATCHKINE MD, KAVER SV. 2004. Cutting edge: human $\mathrm{CD} 4+\mathrm{CD} 25+\mathrm{T}$ cells restrain the maturation and antigen-presenting function of dendritic cells. J Immunol 172: 4676-4680.

32.- MELLOR AL, MUNN DH. 2004. IDO expression by dendritic cells: tolerance and tryptophan catabolism. Nat Rev Immunol 4: 762-774.

33.- MOSMANN TR, CHERWINSKI H, BOND MW, GIEDLIN MA, COFFMAN RL. 1986. Two types of murine helper T cell clone. I. Definition according to profiles of lymphokine activities and secreted proteins. J Immunol 136: 2348-2357.

34.- MOTTET C, GOLSHAYAN D. 2007. CD4+CD25 +Foxp3+ regulatory $\mathrm{T}$ cells: from basic research to potential therapeutic use. Swiss Med. Wkly. 137: 625634.

35.- MURPHY CA, LANGRISH CL, CHEN Y, BLUMENSCHEIN W, MCCLANAHAN T, KASTELEIN RA, SEDGWICK JD, CUA DJ. 2003. Divergent pro- and antiinflammatory roles for IL-23 and IL-12 in joint autoimmune inflammation. J Exp Med 198: 1951-1957.

36.- NAGANUMA M, WIZNEROWICZ EB, LAPPAS CM, LINDEN J, WORTHINGTON MT, ERNST PB. 2006. Cutting edge: critical role for $\mathrm{A} 2 \mathrm{~A}$ adenosine receptors in the T cell-mediated regulation of colitis. J Immunol 177: 2765-2769.

37.- PERRUCHE S, ZHANG P, LIU Y, SAAS P, BLUESTONE JA, CHEN W. 2008. CD3-specific antibodyinduced immune tolerance involves transforming growth factor- $\beta$ from phagocytes digesting apoptotic $\mathrm{T}$ cells. Nat. Med. 14: 528-535.

38.- READ S, MALMSTROM V, POWRIE F. 2000. Cytotoxic $\mathrm{T}$ lymphocyte-associated antigen 4 plays an essential role in the function of $\mathrm{CD} 25+\mathrm{CD} 4+$ regulatory cells that control intestinal inflammation. J Exp Med 192: 295-302.

39.- ROBB RJ, MUNCK A, SMITH KA. 1981. T cell growth factor receptors. Quantitation, specificity, and biological relevance. J Exp Med 154: 1455-1474.

40.- SAKAGUCHI S, ONO M, SETOGUCHI R, YAGI H, HORI S, FEHERVARI Z, SHIMIZU J, TAKAHASHI K, NOMBRA T. 2006. Foxp $3^{+} \mathrm{CD} 25^{+} \mathrm{CD} 4^{+}$natural regulatory $\mathrm{T}$ cells in dominant self-tolerance and autoimmune disease Immunol. Revs 212: 8-27.

41.- SAKAGUCHI S, SAKAGUCHI N, ASANO M, 
ITOH M, TODA M. 1995. Immunologic self-tolerance maintained by activated T cells expressing IL-2 receptor $\alpha$-chains (CD25). Breakdown of a single mechanism of self-tolerance causes various autoimmune diseases. J Immunol 155: 1151-1164.

42.- SAKAGUCHI S, YAMAGUCHI T, NOMURA T, ONO M. 2008. Regulatory $\mathrm{T}$ cells and immune tolerance. Cell 133: 775-787.

43.- SUN CM, HALL JA, BLANK RB, BOULADOUX N, OUKKA M, MORA JR, BELKAID Y. 2007. Small intestine lamina propria dendritic cells promote de novo generation of Foxp3 T reg cells via retinoic acid. J Exp Med 204: 1775-1785.

44.- SURI-PAYER E, AMAR AZ, THORNTON AM, SHEVACH EM. 1998. CD4_CD25_ T cells inhibit both the induction and effector function of autoreactive $\mathrm{T}$ cells and represent a unique lineage of immunoregulatory cells. J Immunol 160: 1212-1218.

45.- TAKAHASHI T, KUNIYASU Y, TODA M, SAKAGUCHI N, ITOH M, IWATA M, SHIMIZU J, SANIGUCHI S. 1998. Immunologic self-tolerance maintained by $\mathrm{CD} 25+\mathrm{CD} 4+$ naturally anergic and suppressive $\mathrm{T}$ cells: induction of autoimmune disease by breaking their anergic/suppressive state. Int Immunol 10: 19691980.

46.- TAKAHASHI T, TAGAMI T, YAMAZAKI S, UEDE T, SHIMIZU J, SAKAGUCHI N, MAK TW, SAKAGUCHI S. 2000. Immunologic self-tolerance main- tained by $\mathrm{CD} 25+\mathrm{CD} 4+$ regulatory $\mathrm{T}$ cells constitutively expressing cytotoxic $\mathrm{T}$ lymphocyte-associated antigen 4. J Exp Med 192: 303-310.

47.- VUKMANOVIC-STEJIC M, ZHANG Y, COOK JE, FLETCHER JM, MCQUAID A, MASTERS JE, RUSTIN MH, TAAMS LS, BEVERLY PC, MACALLAN DC, AKBAR AN. 2006. Human CD4+ CD25hi Foxp3+ regulatory T cells are derived by rapid turnover of memory populations in vivo. J Clin Invest 116: 2423-2433.

48.- WALKER LSK, ABBAS AK. 2002. The enemy within: keeping self-reactive T cells at bay in the periphery. Nat Rev Immunol 2: 11-19.

49.- WORKMAN CJ., VIGNALI DA. 2005. Negative regulation of $\mathrm{T}$ cell homeostasis by lymphocyte activation gene-3 (CD223). J Immunol 174: 688-695.

50.- YAMAZAKI S, IYODA T, TARBELL K, OLSON $\mathrm{K}$, VELINZON $\mathrm{K}$, INABA $\mathrm{K}$, STEINMAN RM. 2003. Direct expansion of functional CD25 + CD4 + regulatory $\mathrm{T}$ cells by antigen-processing dendritic cells. J Exp Med 198: 235-247.

51.- YAMAGUCHI T, SAKAGUCHI S. 2006. Regulatory $T$ cells in immune surveillance and treatment of cancer. Semin. Cancer Biol 16: 115-123.

52.- ZHU J, PAUL WE. 2008. CD4 T cells: Fates, functions, and faults. Blood 112: 1557-1569.

53.- ZIEGLER SF. 2006. FOXP3: of mice and men. Annu Rev Immunol 24: 209-226. 